\title{
A aposta de Fausto e o processo da Modernidade Figurações da sociedade e da metrópole contemporâneas na tragédia de Goethe
}

\author{
MICHAEL JAEGER
}

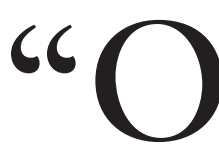

H, PÁRA!” - nessa única exclamação de Fausto reverbera todo o potencial de felicidade e infelicidade da tragédia goethiana. Desvinculada de seu contexto, poder-se-ia pensar que se trata do suspiro de um ser esgotado ou do anelo de um solitário; nesse caso, a exclamação "Oh, pára!" seria um sinal de vida, palavras de alguém que, imerso no torvelinho ininterrupto da existência, suplica por uma trégua para respirar. Se complementarmos o semiverso no texto de Goethe, poderá resultar daí até mesmo uma expressão de ânsia amorosa: "Oh, pára! és tão formoso!". 'Tais significados podem muito bem estar presentes no discurso de Fausto, mas são desviados para uma dimensão subconsciente, pois o verso “Oh, pára! és tão formoso!” representa, antes de mais nada, o componente decisivo daquela aposta diabólica que Fausto fecha com Mefistófeles:

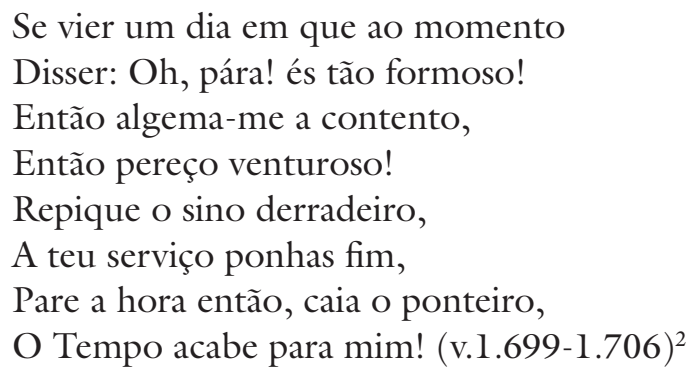

Aos olhos de Fausto, aquele “Oh, pára!” não constitui nenhuma manifestação de vida ou de amor, mas sim um sinal de morte. Pois o momento em que ele desejasse parar, quisesse deter-se porque a existência se lhe afigurasse bela e ele se mostrasse satisfeito com a realidade presente, esse momento deveria ser ao mesmo tempo o de sua morte - o instante, portanto, em que Mefisto, zeloso servo de Fausto durante o seu tempo de vida, assumiria domínio irrestrito sobre sua alma.

O texto de Goethe conhece diversas variações daquela proibição de paz e repouso em face do belo, proibição essa que resulta do pacto entre Fausto e Mefisto. Para citar apenas alguns exemplos: "E mais maldita ainda, a paciência!" (v.1.606), ou "De qualquer forma sou escravo" (v.1.710), ou "Saciemo-nos no 
efêmero momento, / No giro rápido do evento!" (v.1.754-1.755), ou "Entrego-me ao delírio, ao mais cruciante gozo" (v.1.766) e, finalmente, "Este aqui maldito!" (v.11.233). Todo "aqui", todo existir consciente no aqui e no agora é sem valor, árido, morto. Somente aquilo que não está dado, que não se encontra à disposição, apenas o ainda-não-existente é o que atrai e promete a verdadeira vida. Torna-se evidente que dessa proibição do deter-se resulta um culto da velocidade, da inovação desenfreada, da tropelia permanente de imagens e sensações.

Quem de nós, vivendo nos dias de hoje, poderia furtar-se à consciência de que a fórmula fáustica do pacto e da aposta, introjetada já desde muito tempo, determina o nosso comportamento cotidiano? Abre-se diante de nós a possibilidade de enxergar no processo de negação permanente de toda reflexão serena e detida, voltada ao existente, a lei estrutural da moderna sensação de tempo. Inúmeros exemplos do mundo atual das comunicações, do consumo, da economia e da política poderiam ser arrolados aqui para ilustrar a desvalorização de todo momento presente, de todo real efetivo, assim como para demonstrar a atração do não-existente.

Na atual sociedade dominada pela informação e pela mídia, a negação de todos os dados presentes é intensificada até o extremo. Mal ganham forma as imagens e notícias, e de imediato já se vêem desvalorizadas, descartadas pelo seu mero existir. O fluxo permanente, cada vez mais veloz, de imagens, sons, dados e notícias voa sem interrupção, de maneira sempre renovada, rumo à próxima sensação. No mundo das vertiginosas alternâncias de imagens e dos ritmos acelerados que as acompanham, todo deter-se por parte da consciência contemplativa e reflexiva tornou-se, de fato, impossível; não há mais nenhum momento que possa subtrair-se ao furor dinâmico impulsionado pela negação incessante do presente. O pacto de Fausto com Mefisto parece, portanto, exprimir em versão literária e, ao mesmo tempo, de modo preciso e concreto, a lei estrutural da modernidade e, por conseguinte, também do nosso mundo atual.

A Fausto não é possível e nem permitido contentar-se - primeiramente em seu ímpeto por conhecimento e, depois, em sua desesperada obsessão de entretenimento (ou, antes, atordoamento). Ele quer saber tudo, em primeiro lugar coisas novas, possuir continuamente outras coisas, ver imagens inéditas, cada vez mais espetaculares. Em sua vontade de exercer poder sobre a Vida, ele cobiça manipular incondicionalmente os seus elementos - e, em virtude dessa exigência desmedida, fica à mercê do diabo. A proibição fáustica do deter-se, a negação de tudo o que existe no aqui e agora, da realidade momentânea, e o seu almejo insaciável pelo ainda-não-existente, por aquilo que ele não possui, essa disposição de consciência é representada por Mefistófeles. Ao fazer do demônio, na figura de Mefisto, uma valência psíquica de Fausto, Goethe moderniza uma tradição antiqüíssima, proveniente do século XVI, isto é, a história daquele doutor Fausto que, em seu frenético ímpeto por conhecimento e domínio, acaba fazendo um pacto com o demônio. ${ }^{3}$ 
Acompanhado pelo ominoso poodle, Fausto retorna do passeio de Páscoa para o seu solitário gabinete de estudos, onde então Mefisto, sob intensa liberação de fumaça, desentranha-se do cão e apresenta-se como um princípio espiritual, no sentido daquela psicologização:

O Gênio sou que sempre nega!

E com razão; tudo o que vem a ser

É digno só de perecer;

Seria, pois, melhor, nada vir a ser mais.

Por isso, tudo a que chamais

De destruição, pecado, o mal,

Meu elemento é, integral. (v.1.338-1.344)

Esse auto-apresentar-se do espírito da negação tem conseqüências, já que pouco depois Fausto sucumbe à tentação de negar tudo. Pois na aposta, ou no pacto que fecha com o espírito da negação, Fausto converte-se por sua vez em espírito que nega todo existir no presente, nega em si todo momento e todo deter-se consciente e reflexivo, porque de antemão nada do que existe pode satisfazer as suas exigências, e, em conseqüência, revela-se digno de perecer. Se todo deter-se no presente está ameaçado de morte, a angústia perante essa ameaça mortal dá origem a um furor voltado ao consumo da realidade, à demanda de mundo - poder-se-ia falar até mesmo de uma embriaguez de consumo impelida de maneira fóbica. Margarida é a primeira vítima real dessa compulsão de devorar todo o existente, e é também ela que tem a percepção de Fausto e Mefisto como os dois lados de uma mesma medalha. Palavras de Margarida no cárcere, ao perceber Mefisto atrás de Fausto que, a bem da verdade, veio com a intenção de libertá-la:

Que surge do solo lá fora?

Ele! é ele! Vem repeli-lo!

Que busca no sagrado asilo?

Busca-me a mim! (v.4.601-4.604)

Fausto não pode absolutamente repelir Mefisto, mandá-lo embora, uma vez que o tem sempre junto a si em sua angústia em relação ao deter-se e em sua obsessão de consumir pela negação tudo o que existe. E esse Fausto mefistofélico quer efetivamente Margarida, ele a quer devorar, sob o domínio do "apetite" pelo seu corpo (v.2.603). Por isso, exclama Margarida: "Henrique! aterro-me contigo!" (v.4.610).

O horror infundido por Fausto deriva, contudo, de sua angústia, da disposição mefistofélica que o compele a devorar todo ser presente, como deve portarse um espírito que nega continuamente o real, para que não pereça no primeiro momento de comunhão com a realidade do ser, no primeiro gesto do demorar-se e admirar, quando então viesse a exclamar: "Oh, pára! és tão formoso!". Tudo o que acontece na tragédia - e as exceções confirmam a regra - está a serviço das tentativas de Fausto para, por meio da negação do momentaneamente existente, recalcar o seu medo mórbido perante o deter-se, o demorar-se no instante. 
E para essa atitude ininterrupta de recalcamento fica valendo a constatação de caráter histórico: Goethe converte o Fausto mefistofélico em arquétipo da disposição de consciência característica de uma Modernidade que principia na segunda metade do século XVIII e alcança o seu apogeu, ou possivelmente a sua fase final, nos dias que hoje vivemos. Essa época moderna encontra-se sob o signo de dois específicos fenômenos revolucionários, a saber, o permanente revolucionamento político na Europa, que se inicia com a Revolução Francesa, e a permanente revolução econômica nas condições e relações de vida, encetada pela maquinaria do industrialismo no início do século XIX. O texto completo do Fausto goethiano surge entre 1770 e 1831 , exatamente sob esse pano de fundo político-econômico. ${ }^{4}$ Em Fausto. Um fragmento, publicado em 1790 e assinalando o início da história editorial do texto goethiano, são inequívocas as alusões à incipiente Revolução Francesa. E quarenta anos depois, sob o impacto da Revolução Parisiense de julho de 1830, Goethe conclui o trabalho de sua vida no manuscrito fáustico, mas não sem depositar nos lábios do seu herói dramático as posições mais atuais, mais "modernas" dessa era das revoluções. ${ }^{5}$ Tanto para a revolução política como para a revolução econômica dessa época, o princípio da negação é constitutivo. Isso se torna particularmente evidente no âmbito da política revolucionária, a qual nega continuamente o estado de coisas vigente, reconhecido como corrupto e, portanto, como inimigo mortal. Na consciência dos revolucionários, o processo movido pela revolução é idêntico ao processo do movimento histórico. As sentenças proferidas pelos tribunais da Revolução, assim o quer a autoconsciência revolucionária, estão integradas à lógica processual da história e, como negação permanente do respectivo presente político e social, promovem e executam o progresso.

Ao mesmo tempo, porém, o princípio da negação vigora para a revolução econômica da Modernidade, que concebe tudo o que existe no presente como mercadoria, como produto, e surge perante este como espírito que sempre nega, pois tudo que é produzido e lançado no mercado é igualmente digno de logo perecer, de modo a que o processo do desenvolvimento econômico não caia na imobilidade. Assim como o diabo teme a água benta, assim tanto o revolucionário político como o revolucionário econômico, industrial, temem o deter-se. Jamais dirão a um momento, a um estado de coisas, a um produto, aquelas palavras de plenitude e satisfação - “Oh, pára! és tão formoso!” -, pois sempre têm em mira a atração do outro, do não existente, do futuro. ${ }^{6}$

O espírito desse Fausto-Mefisto, espírito que sempre nega, é a imagem literária de Goethe para o pensamento processual que caracteriza a Modernidade, o qual nega todo o existente com vistas ao novo, o ainda-não-existente, o melhor, e tão logo este surja e esteja dado, é por seu turno condenado como insuficiente em nome de um inatingível estado de felicidade localizado sempre no futuro, de modo a logo ser obrigado a "perecer". Esse processo dinâmico da revolução política e econômica, que reúne em si os momentos da negação e inovação, caminha ad infinitum. Por tal motivo, pode Mefisto dizer de Fausto, este arquétipo da revolução moderna: 
E já te prendo em meu enlace.

Deu-lhe o destino um gênio ardente

Que, invicto, aspira para a frente

E, em precipitação fugace,

Da terra o Bom transpõe, fremente. (v.1.855-1.859)

"Sempre para a frente" - assim se formula a palavra de ordem progressista típica da época. ${ }^{7}$ A despeito das notas críticas que ressoam no texto goethiano, em consonância com as quais a aspiração de Fausto se mostra sempre frenética e desgostosa, uma vez que ele jamais consegue deter-se no "Bom", nas alegrias presentes, mas salta imediatamente sobre essas no anseio por prazeres novos, melhores, futuros - a despeito de tais notas críticas subliminares, Fausto foi considerado até recentemente como representante do modelo de progresso da Modernidade e de suas esperanças profanas de redenção. No acervo de citações dessa tendência exegética, entraram versos do ativismo fáustico: "Patenteia-se o homem na incessante ação" (v.1.759), "Ao homem apto, este mundo acomoda" (v.11.446), "No avanço, encontre ele êxtase ou tormento, / Insatisfeito embora, hoje e a qualquer momento!" (v.11.451-11.452). ${ }^{8}$

$\mathrm{E}$, de fato, Goethe mostra a aspiração fáustica, sobretudo na segunda parte do drama, nos mais importantes estádios do moderno revolucionamento das condições e relações de vida. Mostra-a no Palatinado Imperial, onde Fausto e Mefisto introduzem o papel-moeda e deflagram o fluxo de capital que varre do mapa o velho mundo do feudalismo e financia os gigantescos projetos técnicos, industriais e de transportes da Modernidade. É-nos dado olhar dentro do laboratório do Dr. Wagner, o antigo fâmulo de Fausto, onde um homem está sendo criado nas retortas. Essa produção técnico-industrial de um ser humano (clonagem, como se diria hoje) configura-se como verdadeira meta daquele projeto da Modernidade de negar a primeira criação, a existência que deriva da Natureza, e substituí-la pela segunda criação, que é um produto do moderno processo de produção.

No final do drama, Fausto nos dá um exemplo dessa revolução moderna e, portanto, da inversão de todas as relações naturais e de produção. Nós o vemos primeiramente na orla marítima, onde ele manifesta o desejo de lutar contra as ondas, lutar contra os elementos e submetê-los ao princípio industrial de produtividade e desempenho (ver v.10.198 e seguintes); e nas últimas cenas terrenas da tragédia nós o vemos numa nova terra, que ele conquistou ao mar por intermédio de colossais construções de diques e canais. Nesse mundo novo, artificialmente produzido, ouvimo-lo por fim pronunciar os famosos versos:

Sim! da razão isto é a suprema luz,

A esse sentido, enfim, me entrego ardente:

À liberdade e à vida só faz jus,

Quem tem de conquistá-las diariamente.

E assim, passam em luta e em destemor,

Criança, adulto e ancião, seus anos de labor.

Quisera eu ver tal povoamento novo,

E em solo livre ver-me em meio a um livre povo. (v.11.573-11.580) 
No final, a aposta fáustica, a negação da permanência, passa a vigorar por toda parte. Contemplamos então a imensa história de sucesso do moderno ideal de movimentação, ao qual obedece agora toda a sociedade - "criança, adulto e ancião" - e esta é uma história de êxito não apenas no enredo dramático. Pois no Fausto de Goethe, em especial na sua segunda parte, podemos reconhecer também a expressão literária de nossa sociedade moderna, a prefiguração do ritmo vertiginoso das metrópoles contemporâneas, uma Brasília, por exemplo, erigida num esforço titânico em pouquíssimo tempo. Essa capital, aliás, poderia ter sido construída por Fausto, uma vez que não está distante de seu ideal desenvolvimentista, não seria estranha ao seu projeto colonizatório, que Goethe configura, porém, de modo irônico como espécie de utopia de uma modernidade que viria a ter o seu símbolo mais ostensivo justamente na arquitetura. Como na colônia de Fausto, também nas metrópoles atuais impera a vontade construtivista do homem moderno, e não seria surpreendente se, em meio a anotações do arquiteto da capital brasileira, por exemplo, se encontrassem pensamentos de inspiração genuinamente fáustica.

Seria lícito sustentar assim que a utopia de dinamismo que na tragédia goethiana deriva do pacto - "Quisera eu ver tal povoamento novo" - tenha se convertido nesse meio tempo em realidade: hoje não há nenhuma região da consciência, nenhum lugar, mesmo entre os mais isolados da Terra, que não tenha sido alcançado pela moderna negação do deter-se, já que o mundo todo se assemelha àquele "povoamento novo" que fervilha em movimentos cada vez mais acelerados de imagens, dados, finanças, consumo e transportes.

A uma utopia, contudo, não pode acontecer nada pior do que ser colocada em prática, uma vez que ela perde assim a fascinante aura da promessa redentora. Ao longo de 150 anos, Fausto foi festejado como personagem de identificação; mas, desde que sua utopia daquele povoamento fervilhante tornou-se realidade, vivenciamos uma mudança de paradigma na exegese do drama, uma vez que descobrimos o seu potencial crítico e, desse modo, passamos a nos perguntar o que seria assim tão pernicioso no deter-se, no demorar-se no presente. Por que tudo o que existe precisa ser permanentemente desvalorizado, por que todo espaço de repouso e serenidade tem de ser colonizado no sentido da moderna lei do dinamismo e arrastado para aquele fervilhar generalizado? Quais são os custos reais - assim nos perguntamos hoje em dia - do princípio moderno da intensificação incessante do movimento; quem e o que é atropelado pela mobilização geral a serviço da permanente negação do presente? Na tragédia goethiana são, ao lado de Margarida e de um Peregrino - possivelmente o próprio Goethe -, os dois anciãos, Filemon e Baucis, que vão parar debaixo das rodas, pois não podem integrar-se tão depressa assim ao novo ritmo, e tampouco querem integrar-se porque representam uma cultura inteiramente diferente, isto é, a cultura do deter-se calmo, da serenidade, e, por conseqüência, atraem sobre si o furor fáustico da negação. 


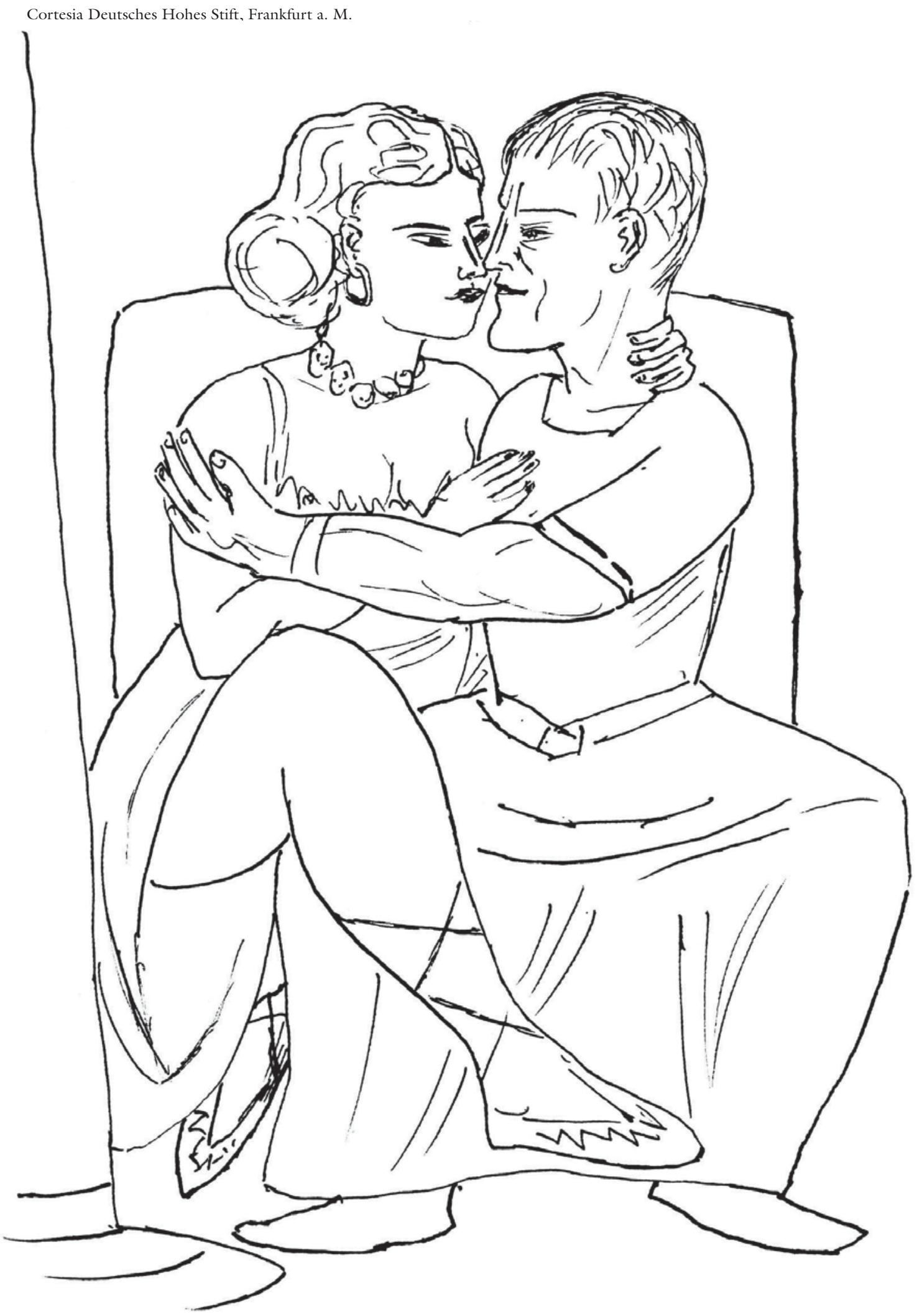

Fausto e Helena: "Somente o presente é a nossa felicidade". Ilustração de Max Beckmann. 


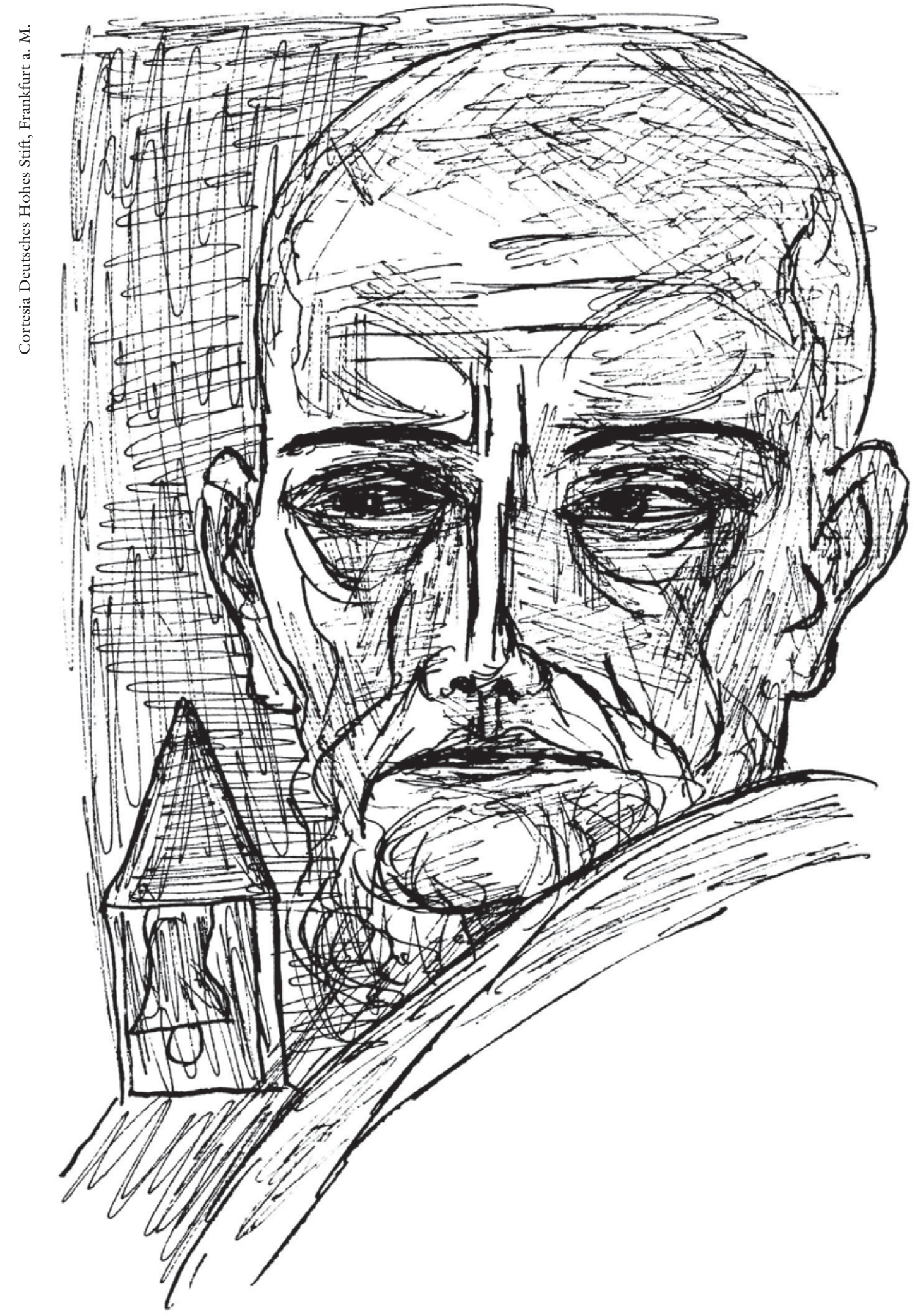

"Fausto, em idade bíblica, caminhando imerso em meditação". Ilustração de Max Beckmann. 
No nosso mundo determinado por ritmos dinâmicos inescapáveis e de validade global, em que a exclamação “Oh, pára!”, agora de maneira inteiramente não-fáustica, não mais nos surge como sinal de morte, mas sim de vida, nessa situação atual nós nos perguntamos se a famosa aspiração de Fausto por aquele povoamento final não representa antes um desnorteamento, a rota para um beco sem saída, para o "eterno-vazio", o qual se nos escancara então como Horror vacui, uma vez que nos foi negado e suprimido todo ponto de repouso e, de modo geral, tudo o que existe no presente.

Paradoxalmente são tais questões atuais e candentes que a tradição da história fáustica traz de volta à nossa lembrança. Desde o século XVI, a história de Fausto vem se configurando como um tema popular com variações específicas de cada época, não apenas na literatura, mas também na música e, sobretudo, nas artes plásticas, âmbito este ao qual será lançado um breve olhar à guisa de conclusão.

O drama goethiano sempre ofereceu às diferentes épocas o modelo literária para a elucidação da respectiva auto-imagem mediante um questionamento tipicamente fáustico: quão longe podemos ir na satisfação de nossas necessidades? Haveria um limite à nossa aspiração por felicidade, riqueza e domínio? Caso haja esse limite, onde começaria o pacto demoníaco? Tais questões encerram o problema antropológico fundamental de determinar a relação entre Eu e mundo, subjetividade e objetividade - e a esse problema Goethe confere forma literária concreta em sua nova modulação do tema fáustico na primeira parte da tragédia, mais precisamente por meio da contundente pergunta que Gretchen dirige a Fausto: "Dize-me, pois, como é com a religião?" (v.3.415). Já no final da segunda parte da tragédia, parece ser o próprio Goethe que, no gesto típico do iluminista que exorta à auto-reflexão crítica, dirige à Modernidade, num sentido mais amplo, aquela pergunta de Gretchen: Seria possível uma vida inteiramente desprovida de religião? Na perspectiva da velhice, religião não deve ser entendida num sentido ortodoxo, mas sim na chave geral de uma espiritualidade sincrética, pós-crítica e pós-iluminista, tal como caracteriza as paragens venturosas de Filemon e Baucis sob o signo do "eterno Deus" (v.11.142) - paragens, contudo, que serão extintas pelo moderno projeto colonizador de Fausto. Esse mesmo sincretismo espiritual irá caracterizar depois os enigmáticos versos “celestiais" no final da tragédia. No horizonte aberto da obra de velhice Fausto II e na consciência da ruptura revolucionária com a tradição, a atualização goethiana da pergunta de Gretchen se formula em relação à possibilidade de uma vida desprovida de todo e qualquer pensamento de transcendência, tal como se expressa nas palavras de Fausto: "Que importam do outro mundo os embaraços?” (v.1.660), “À nossa vista cerra-se o outro mundo; / Parvo quem para lá o olhar alteia" (v.11.442-11.443). Haveria ainda algo sagrado para nós, para a nossa cultura - assim se coloca hoje a pergunta de Gretchen -, sagrado, porém, numa concepção mais geral; haveria algo de valor insofismável e insubstituível, perante o qual é imperioso deter-se, sobre o qual o fervilhamento generalizado 
e global não deveria passar exercendo o recalque e a negação? Hoje, portanto, a pergunta de Gretchen que nos é dirigida, à aspiração fáustica em nosso íntimo, diz: "Haveria ainda um tabu?".

A pergunta que Margarida dirige a Fausto é atemporal, uma vez que cada época define a sua auto-imagem por intermédio dessa pergunta, passando primeiramente pela determinação da relação entre religiosidade e profanidade uma relação, contudo, que no horizonte literário da tragédia de Goethe deve ser compreendida como expressão concreta e ao mesmo tempo simbólica dos liames mais gerais e profundos entre o "deter-se" e o "aspirar", entre repouso e movimento, reflexão e ação, contemplação mundana e revolução mundial.

Como, porém, se formula a resposta goethiana à pergunta de Gretchen? Goethe nunca foi particularmente pio, pelo menos não em sentido confessional, motivo pelo qual sempre foi hostilizado pela ortodoxia teológica e seus partidos radicais, que o consideravam representante típico de uma civilização moderna iluminista-liberal e alheia à religião ("ateísta”). Mas, apesar dessa imagem hostil, na perspectiva de uma história das idéias se haverá de constatar: religioso de um modo mais amplo, isso Goethe certamente foi, ou seja, naquela acepção original e literal da religio como veneração espiritual perante o que é indisponível e inacessível à vontade humana de poder, perante aquilo a que Goethe pôde dar o nome decididamente não-ortodoxo de "Eterno-feminino" e que ele encontrava sobretudo na contemplação da Natureza, "in herbis et lapidibus" - muito ao contrário da impulsiva e obcecada vontade fáustica de arrancar a Ísis o seu véu, de agarrar-se ao seio da Natureza (v.455 e seguintes) e submetê-la ao seu projeto de colonização e progresso. E é no sentido dessa espiritualidade livre, interpretável tanto em chave religiosa como na filosófica, que se há de compreender aquele fundamental verso místico no final da tragédia: “Tudo o que é efêmero / É apenas pré-existência”.

Aquém da mística não-convencional e da contemplação espiritual da $\mathrm{Na}$ tureza, a resposta de Goethe à pergunta de Gretchen pela relação entre “deterse" e "aspirar" - pergunta tão virulenta em tempos de crises e rupturas - pode ser percebida na Arte, e de maneira particularmente nítida em seu Fausto. Pois a concreta resposta goethiana ao moderno furor de negação, colonização e movimento foi a própria Arte, e em especial uma arte inteiramente alheia ao ideal moderno de dinamicidade e progresso, mas que, em vez disso, reverencia o ideal do Classicismo, precisamente aquele momento do deter-se contemplativoreflexivo, ou mesmo espiritual, em face do Belo, o qual Fausto amaldiçoa em sua angústia mórbida. É o próprio Kairós da filosofia antiga e de suas doutrinas eudemonistas, o momento pleno do reconhecimento do verdadeiramente existente - um ideal, portanto, que não pode ser superado por nada, por nenhum progresso e por nenhuma das deslumbrantes promessas do futuro. Esse ideal de consciência, vida, felicidade e beleza porta, na tragédia goethiana, o nome de Helena. A Fausto é dado contemplar Helena, a mais bela mulher, vê-la na Grécia, em um lugar por assim dizer extraterritorial, num interlúdio do drama. 


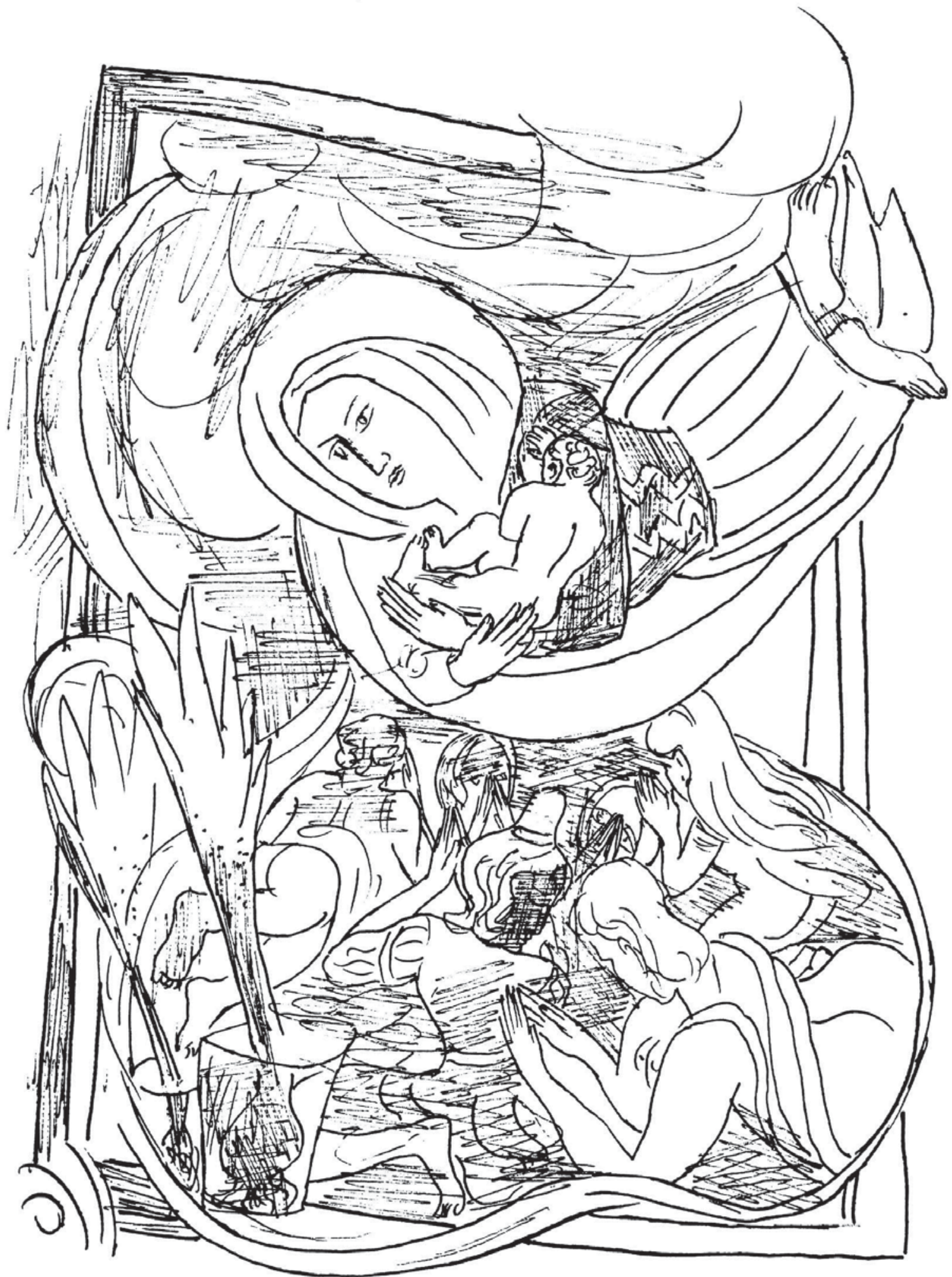

"Mater Gloriosa" (1944). Ilustração de Max Beckmann. 
E na Arcádia, ao lado de Helena, vigora a sentença: "Somente o presente é a nossa felicidade". É esse o ideal de vida goethiano. ${ }^{9}$ É a inversão exata do pacto, da regra fáustica segundo a qual se deveria dizer: "Somente o presente é a nossa infelicidade", motivo pelo qual nós, contemporâneos modernos no espírito de Fausto, não podemos nos deter nem por um instante sequer e temos de marchar para o ainda-não-existente como que sobre um chão em brasas, sempre acossados pelos ritmos inexoráveis de uma dinâmica onipresente, sempre insatisfeitos, em permanente inquietação, em meio a uma caçada infindável pela riqueza e felicidade presumivelmente sempre maiores, que jamais se oferecem no presente, pois se evadindo sem cessar para o futuro.

Essa dimensão frenética e vertiginosa que Goethe, movido por inequívoca intenção crítica, imprimiu à tragédia fáustica foi captada com grande sensibilidade por alguns de seus ilustradores, e cumpriria mencionar aqui, em primeiro lugar, o pintor francês Eugène Delacroix (1798-1863). Com efeito, a disposição para a inquietude, a obsessão impulsiva por agitação, a embriaguez de velocidade como marca característica da existência tipicamente moderna de Fausto - tudo isso foi convertido em imagem, com extrema intensidade e pregnância, no ciclo de dezessete litografias que Delacroix concluiu em 1828 e que originalmente ilustraram a tradução francesa de Frédéric Stapfer, publicada nesse mesmo ano. ${ }^{10}$

Quanto ao Fausto II, destacam-se certamente as ilustrações realizadas por Max Beckmann (143 desenhos a bico-de-pena) entre 15 de abril de 1943 e 15 de fevereiro de 1944 em Amsterdã, cidade de seu exílio entre 1937 e 1947. Pouco mais de um século após a publicação da segunda parte da tragédia, Beckmann, um dos mais relevantes artistas do século XX, retoma o olhar crítico que Goethe lançou sobre os inícios da nova era e o traduz, em suas ilustrações do Fausto, na auto-reflexão crítica do artista moderno e, indo mais além, na auto-reflexão crítica da Modernidade como tal. Os desenhos de Beckmann, não raro com traços de auto-retrato, mostram Fausto como personalidade dilacerada, exemplarmente moderna, cujo estado de consciência corresponde à crítica situação do mundo contemporâneo. Dificilmente se poderia conceber antinomia mais expressiva às interpretações otimistas (e "perfectibilistas") do Fausto do que esses retratos de Beckmann que lançam o homem moderno num universo de insegurança, angústia e apreensão. De modo conseqüente, o artista baniu essa atmosfera sombria apenas dos desenhos da clássica natureza arcádica, repetindo de maneira exata a frágil, possivelmente resignada reflexividade na constelação criada por Goethe. E, no sentido dessa correspondência congenial entre literatura e artes plásticas, valeria observar, por fim: do mesmo modo como os místicos versos finais de Goethe, também as imagens finais, e não menos místicas, de Beckmann são inteiramente inacessíveis à lógica processual da moderna ideologia do progresso e às suas promessas secularizadas de felicidade e redenção. ${ }^{11}$ 
Notas

1 As citações seguem a edição Faust. Eine Tragödie preparada por Albrecht Schöne (Frankfurt, 1994). A versão em português dos versos citados corresponde à tradução de Jenny Klabin Segall publicada em 2004 (Fausto. Uma tragédia - Primeira Parte) e 2007 (Fausto. Uma tragédia - Segunda Parte).

2 A proibição do "parar", do "deter-se", é precedida pelo fechamento da aposta entre Fausto e Mefistófeles: "FAUSTO: Se eu me estirar jamais num leito de lazer, / Acabese comigo, já! / Se me lograres com deleite / E adulação falsa e sonora, / Para que o próprio Eu preze e aceite, / Seja-me aquela a última hora! Aposto, e tu? MEFISTÓFELES: Topo!" (v.1.692-1.698). A aposta, por seu turno, decorre da conjectura de Fausto acerca de um possível pacto que o vincularia a Mefisto: "FAUSTO: O inferno, até, tem leis? mas, bravos! / Podemos, pois, firmar convosco algum contrato, / Sem medo de anular-se o pacto?" (v.1.413-1.415).

3 Quanto à proveniência da figura de Fausto a partir do ambiente teológico e protestante do século XVI, e ainda quanto à tradição dos livros históricos sobre o Doutor Fausto, ver o estudo de Jochen Schmidt Goethes Faust. Erster und Zweiter Teil. Grundlagen. Werk. Wirkung [O Fausto de Goethe. Primeira e segunda partes. Fundamentos. Obra. Efeito] (Munique, 2001, p.11-33). Ver também, à p.122 e seguintes, a elucidação que faz Schmidt, com fundamentos históricos, da modernização da arcaica figura do diabo, levada a cabo por Goethe ao fazer de Mefisto uma valência psíquica de Fausto. $\mathrm{Na}$ perspectiva dessa psicologização, as conversas entre Fausto e Mefisto podem ser entendidas como monólogos daquele.

4 Sobre esse período revolucionário na Europa como pano de fundo da tragédia e, de um modo geral, sobre a fenomenologia goethiana da incipiente Modernidade, ver o meu estudo Fausts Kolonie - Goethes kritische Phänomenologie der Moderne [ A colônia de Fausto - A fenomenologia critica da modernidade empreendida por Goethe] (Würzburg, 2004).

5 Isso foi demonstrado de maneira particularmente expressiva no caso das doutrinas présocialistas e industrialistas de Saint-Simon e dos sant-simonistas, que Goethe incorporou, por vezes em citações literais, em cenas do Fansto redigidas em 1831. Quem primeiro apontou para esse aspecto foi Gottlieb C. L. Schuchard: "Julirevolution, St. Simonismus und die Faustpartien von 1831" [ "Revolução de julho, saint-simonismo e as partes do Fausto de 1831"], in: Zeitschrift für deutsche Philologie 60 (1935). Ver também, a esse respeito, o ensaio de Nicholas Boyle "The politics of 'Faust II'. Another look at the stratum of 1831", in: Publications of the English Goethe Society, v.52 (1981/1982), p.4-43.

6 A respeito do princípio da negação que caracteriza o pensamento processual da revolução política e econômica na Modernidade, e, ainda, a respeito da reflexão crítica que Goethe empreende em seu Fausto sobre tais fenômenos processuais de negação, ver o meu ensaio "Fausts Revolution" ["A revolução de Fausto"], in: Verweile doch. Goethes Faust heute [Oh, pára! o Fausto de Goethe hoje] (organizado por Michael Jaeger; Blätter des Deutschen Theaters, 2006, p.103-14).

7 Sintomaticamente, Goethe insere tais versos no manuscrito da tragédia somente após o seu retorno da Itália e sob o impacto da fase inicial da Revolução Francesa. A versão mais antiga, o assim chamado Urfaust (Fausto original), ainda não contém esses versos típicos e representativos da época da Revolução. A gênese textual, cujo conhe- 
cimento possibilita ilações sobre o crescente potencial histórico e crítico da tragédia redigida ao longo de décadas, pode ser acompanhada à luz da edição sinóptica do Fausto I organizada por Werner Keller: Urfaust; Faust. Ein Fragment; Faust. Eine Tragödie. Paralleldruck der drei Fassungen [Fausto original; Fausto. Um Fragmento; Fausto. Uma Tragédia. Impressão paralela das três versões] (Frankfurt a.M., 1985).

8 Foi a recepção "socialista” (em seu sentido mais amplo) da tragédia goethiana que construiu a exegese "perfectibilista" mais conseqüente, mais bem elaborada filosoficamente, tomando o seu ponto de partida nas especulações teóricas de Hegel sobre o Fausto: Georg Lukács, na chave de um marxismo mais rigoroso, e Ernst Bloch, numa perspectiva utópica e não-ortodoxa, para citar apenas dois proeminentes exemplos do século XX.

9 Pierre Hadot, em seu grandioso estudo sobre a tradição do exercitium spirituale, discute o caráter eudemonista da espiritualidade clássica de Goethe, seus antigos textos de referência e a tradição desses na história da filosofia e da religião (P. Hadot. Exercices spirituels et philosophie antique [Paris, 1987] - ver, em especial, o capítulo sobre Goethe, p.101-22, intitulado justamente "Somente o presente é a nossa felicidade").

10 Essa constatação pode ser atualizada com a edição bilíngüe do Fausto I publicada pela Editora 34 (2004), em tradução de Jenny Klabin Segall, com notas e comentários de Marcus V. Mazzari e ilustrações de Delacroix.

11 A recente edição brasileira da segunda parte da tragédia, novamente em tradução de J. K. Segall (Editora 34, 2007), propicia ao leitor a possibilidade de colocar à prova essas observações sobre a relação entre os desenhos de Beckmann e o substrato crítico do Fausto II.

Michael Jaeger é docente na Universidade Livre de Berlim. Publicou, entre outros, o estudo Fausts Kolonie - Goethes kritische Phänomenologie der Moderne [A colônia de Fausto - A fenomenologia critica da modernidade empreendida por Goethe] (Würzburg, 2004). Mais recentemente, organizou o volume Verweile doch. Goethes Faust heute [Oh, pára! o Fausto de Goethe hoje] (Blätter des Deutschen Theaters, 2006). @ -Asmljaeger@aol.com

Tradução de Marcus Vinicius Mazzari. O original em alemão - "Fausts Wette und der Prozeß der Moderne" - encontra-se à disposição do leitor no IEA-USP para eventual consulta.

Recebido em 1․2.2007 e aceito em 13.2.2007. 